\title{
Pré-tratamento com somatotropina bovina (rbST) na superovulação de doadoras da raça Holandesa
}

[Pre-treatment with bovine somatotropin (rbST) in the superovulation of Holstein donors]

\author{
E.F. Neves ${ }^{1,3}$, A.F. $\operatorname{Ramos}^{1,3}$, A.P. Marques Júnior ${ }^{2 *}$ \\ ${ }^{1}$ Doutorando em Ciência Animal - UFMG \\ ${ }^{2}$ Escola de Veterinária - Universidade Federal de Minas Gerais \\ Caixa Postal 567 \\ 30123-970 - Belo Horizonte, MG \\ ${ }^{3}$ Bolsista CNPq
}

\begin{abstract}
RESUMO
Estudou-se o efeito da somatotropina bovina recombinante (rbST) sobre o número e qualidade dos embriões de 40 vacas da raça Holandesa, distribuídas aleatoriamente em três grupos: controle (GI, n=15), tratadas com 250mg de rbST (GII, n=11) e tratadas com 500mg de rbST (GIII, n=14) no sexto dia do ciclo estral. No décimo dia após o estro, as doadoras foram submetidas ao tratamento superovulatório com 360mg de hormônio folículo estimulante (FSH) em doses decrescentes, duas vezes ao dia, com intervalos de 12 horas. Juntamente com a sétima aplicação de FSH foram administrados 0,5mg de cloprostenol (análogo da $\mathrm{PGF}_{2 \alpha}$ ) e as doadoras inseminadas artificialmente 12, 20 e 28 horas após o início da manifestação de estro. Os embriões foram coletados, não cirurgicamente, no sétimo dia após a primeira inseminação. A administração de 250 ou 500mg de rbST aumentou $(\mathrm{P}<0,05)$ o percentual de embriões viáveis e não alterou a taxa de gestação das receptoras.
\end{abstract}

Palavras-chave: embrião, somatotropina, taxa de gestação

\begin{abstract}
The use of recombinant bovine somatotropin ( $r b S T)$ in superovulated Holstein donors to increase the number and quality of the embryos was studied. Forty cows were randomly allotted into three groups: control ( $n=15)$, treated with $250 \mathrm{mg}$ rbST $(n=11)$ and treated with $500 \mathrm{mg}$ rbST $(n=14)$ on the $6^{\text {th }}$ day of the oestrous cycle. On the $10^{\text {th }}$ day after estrus the donors were submitted to a superovulatory treatment with 360mg of FSH in decreasing doses, twice-a-day, with 12 hours interval. Along with the $7^{\text {th }}$ application of FSH, 0.5mg of cloprostenol was injected and the donors were inseminated 12, 20 and 28 hours after the onset of estrus. Embryos were collected non-surgically on the $7^{\text {th }}$ day after the $1^{\text {st }}$ insemination. The use of 250 or $500 \mathrm{mg}$ of rbST increased $(P<0.05)$ the percentage of viable embryos, but did not alter the recipient pregnancy rate.
\end{abstract}

Keywords: embryo, pregnancy rate, somatotropin

\section{INTRODUÇÃO}

A transferência de embriões (TE), biotecnia que possibilita a coleta simultânea de mais de um embrião e sua transferência para receptoras, ou seu congelamento, tem sido difundida em rebanhos tecnificados e proporcionado ganho genético, pelo aumento do número de descendentes de animais geneticamente superiores (Drost et al., 1999).

Recebido para publicação, em 26 de abril de 2004

Recebido para publicação, após modificações, em 13 de outubro de 2004

* Autor para correspondência (correponding author)

E-mail: ampinho@ufmg.br 
O sucesso dos programas de transferência de embriões depende, na maioria das vezes, da eficiência da superovulação (Callesen et al., 1996), fator limitante atribuído à ampla variedade na resposta ao tratamento superovulatório, que está diretamente relacionado com a população de folículos presentes no ovário e com a resposta deles ao estímulo de gonadotropinas exógenas (Gong et al., 1997).

A utilização da somatotropina bovina recombinante em doadoras, no início do ciclo estral, tem sido pesquisada com o objetivo de aumentar a população de folículos antrais recrutados $\mathrm{e}$, conseqüentemente, melhorar a resposta superovulatória (Gong et al., 1996). Estudos in vivo em raças européias de corte demonstraram que injeções de somatotropina bovina recombinante (rbST) induziram o aumento da população de folículos antrais com diâmetro entre 2 e $5 \mathrm{~mm}$ (Gong et al., 1993).

Este estudo teve o objetivo de verificar o efeito da utilização de rbST, em doses de 250 ou $500 \mathrm{mg}$, na resposta superovulatória de doadoras da raça Holandesa.

\section{MATERIAL E MÉTODOS}

O experimento foi conduzido em uma central de transferência de embriões localizada no município de Funilândia, MG.

Foram utilizadas 40 doadoras de embriões da raça Holandesa, não-lactantes, alojadas na central de transferência de embriões. Durante o período experimental as doadoras foram mantidas em piquete de exercício, com sombreamento natural, e alimentadas, duas vezes ao dia, com capim-elefante (Pennisetum purpureum) picado. Como receptoras foram disponibilizadas 182 fêmeas mestiças, na maioria novilhas, mantidas a pasto, com predomínio de Braquiaria brizanta. Todos os animais receberam sal mineral e água à vontade.

As doadoras e receptoras foram submetidas a exame clínico e ginecológico de rotina, além de exames para tuberculose e brucelose e vacinadas contra IBR/BVD, leptospirose, raiva e febre aftosa.
As doadoras foram distribuídas aleatoriamente em três grupos experimentais: grupo I $(n=15)$, tratadas com FSH e solução salina, grupo II $(\mathrm{n}=11)$, tratadas com FSH e $250 \mathrm{mg}$ de rbST e grupo III $(n=14)$, tratadas com FSH e $500 \mathrm{mg}$ de rbST. As doadoras, após o exame clínico e ginecológico e pelo menos dois ciclos estrais normais, foram tratadas no sexto dia, em média, por via subcutânea, na fossa ísquio-retal. No $10^{\circ}$ dia após o estro, em média, todas as doadoras foram superovuladas com 360mg de hormônio folículo estimulante ${ }^{1} \quad$ (FSH) em doses decrescentes, com intervalo de 12 horas entre aplicações, durante quatro dias consecutivos. Na sétima aplicação de FSH foi também administrado 0,5mg de cloprostenol ${ }^{2}$ (análogo da $\mathrm{PGF}_{2 \alpha}$ ). As doadoras foram inseminadas artificialmente em horários fixos, 12,20 e 28 horas após a observação do estro. As observações foram realizadas duas vezes por dia, pela manhã e à tarde.

A coleta dos embriões foi realizada por método não cirúrgico, no sétimo dia após a primeira inseminação, por meio de lavagem uterina utilizando solução de $\mathrm{PBS}^{3}$ (tampão salinafosfato) de Dulbecco e Vogt modificado por Whittingham (1971). O lavado uterino foi filtrado em filtro para embriões ${ }^{4}$, colocado em placa de Petri de $12 \mathrm{~cm}$ de diâmetro e examinado em microscópio estereoscópico ${ }^{5}$ para busca, classificação e avaliação das estruturas. As estruturas identificadas e classificadas foram transferidas, com o auxílio de micropipetas de vidro, para uma placa de Petri de $3,5 \mathrm{~cm}$ de diâmetro, contendo solução de tampão ${ }^{6}$ acrescida de albumina sérica bovina (BSA). Os embriões foram classificados quanto ao estádio de desenvolvimento (oócito, mórula, blastocisto inicial, blastocisto, blastocisto expandido e blastocisto eclodido) e avaliados qualitativamente (excelente, bom, regular, pobre e degenerado) segundo Manual... (1998).

\footnotetext{
${ }^{1}$ Foltropina de hipófise suína - Folltropin ${ }^{\circledR}-V$, Vetrepharm Inc.

${ }^{2}$ Cloprostenol sódico - Ciosin $^{\circledR}$, Coopers do Brasil

${ }^{3}$ Dulbecco modificado $P B S$ - Laboratório Cultilab

${ }^{4}$ Malha de $80 \mu$ - Millipore

${ }^{5}$ Zeiss - West Germany

${ }^{6}$ Tampão Zwitterionic e 0,4 \% albumina sérica bovina-fração V gentamicina, anfotericina B - Embriocare - São Paulo, SP
} 
Os embriões viáveis, classificados qualitativamente como excelente, bom, regular e pobre, foram transferidos para receptoras previamente selecionadas, pelo método cirúrgico, por laparotomia no flanco ipsilateral ao ovário com corpo lúteo (CL) previamente identificado por palpação retal. Por ocasião do exame ginecológico prévio à inovulação, o corpo lúteo foi classificado qualitativamente em função do seu tamanho e consistência como corpo lúteo bom (CL1), muito bom (CL2) e excelente (CL3). Foi considerada satisfatória a assincronia de aproximadamente 48 horas entre o período de manifestação de estro das receptoras e doadoras. A taxa de fertilização foi obtida pelo percentual de estruturas viáveis e degeneradas em relação ao total de estruturas coletadas, segundo Hasler et al. (1987).

O diagnóstico de gestação foi realizado de 55 a 65 dias após a inovulação dos embriões, com auxílio de aparelho ultra-sonográfico com transdutor linear endoretal de 6.0 MHz.

O delineamento estatístico utilizado foi inteiramente ao acaso. Para a comparação de médias do total de estruturas e de embriões viáveis usou-se teste não-paramétrico KruskalWallis. Para a análise da taxa de gestação foi utilizado o teste de qui-quadrado segundo Sampaio (2002).

\section{RESULTADOS E DISCUSSÃO}

Dos 40 animais superovulados, 86,7\%, 100\% e $78,6 \%$ dos animais dos grupos I, II e III, respectivamente, responderam ao tratamento com coleta de estruturas. Vinte por cento dos animais do grupo I, $18 \%$ do II e $21,4 \%$ do III não produziram embriões viáveis, isto é, não houve diferença entre os grupos quanto à resposta ao tratamento e ao percentual de fêmeas que produziram embriões viáveis $(\mathrm{P}>0,05)$. Dos três animais $(7,5 \%)$ que não responderam ao tratamento, dois $(13,3 \%)$ eram do grupo I e um $(7,1 \%)$ do grupo III. A resposta das doadoras foi homogênea: $13,1 \%$ no grupo I produziram $30 \%$ dos embriões, $27,3 \%$ no grupo II produziram $61,2 \%$, e $14,2 \%$ no grupo III, $64,6 \%$.

Não houve diferença $(\mathrm{P}<0,05)$ no número de estruturas totais, embriões viáveis e taxa de fertilização entre os grupos. $\mathrm{O}$ percentual de embriões viáveis foi diferente $(\mathrm{P}<0,05)$ segundo o tratamento (Tab. 1), sinalizando que a utilização de rbST, independente da dose, aumentou o percentual de embriões viáveis, provavelmente em decorrência da ação direta ou indireta da rbST no estímulo metabólico de folículos antrais que normalmente entrariam em atresia (Gong et al., 1996).

Tabela 1. Média, desvio-padrão (DP) e número total de estruturas coletadas e embriões viáveis, taxas de gestação e de fertilização por grupo experimental de doadoras da raça Holandesa

\begin{tabular}{lccc}
\hline & $\begin{array}{c}\text { Grupo I } \\
(\text { controle }) \\
(\mathrm{n}=15)\end{array}$ & $\begin{array}{c}\text { Grupo II } \\
(250 \mathrm{mg} \mathrm{rbST}) \\
(\mathrm{n}=11)\end{array}$ & $\begin{array}{c}\text { Grupo III } \\
(500 \mathrm{mg} \text { rbST }) \\
(\mathrm{n}=14)\end{array}$ \\
\hline Total de estruturas coletadas & 127 & 103 & 124 \\
Média \pm DP do total de estruturas coletadas & $8,47 \pm 5,60 \mathrm{a}$ & $9,36 \pm 8,73 \mathrm{a}$ & $8,86 \pm 6,88 \mathrm{a}$ \\
Total de embriões viáveis & 50 & 65 & 67 \\
Média \pm DP de embriões viáveis & $3,33 \pm 2,61 \mathrm{a}$ & $5,91 \pm 9,31 \mathrm{a}$ & $4,79 \pm 5,59 \mathrm{a}$ \\
Embriões viáveis* & $39,37 \% \mathrm{~b}(50 / 127)$ & $63,11 \% \mathrm{a}(65 / 103)$ & $54,03 \% \mathrm{a}(67 / 124)$ \\
Taxa de gestação & $68,00 \% \mathrm{a}(34 / 50)$ & $56,92 \% \mathrm{a}(37 / 65)$ & $58,20 \% \mathrm{a}(39 / 67)$ \\
Taxa de fertilização & $60,63 \% \mathrm{a}$ & $67,96 \% \mathrm{a}$ & $71,77 \% \mathrm{a}$ \\
\hline
\end{tabular}

Valores seguidos de letras distintas na mesma linha diferem entre $\operatorname{si}(\mathrm{P}<0,05)$.

* Análise de dispersão de freqüência (qui-quadrado).

Taxa de fertilização: percentual de estruturas viáveis e degeneradas do total de estruturas coletadas.

Estes resultados são semelhantes ao de estudos que utilizaram rbST antes, durante e após a superovulação (Kuehner et al., 1993; Gong et al., 1996; Cushman et al., 2001). O mecanismo pelo qual o rbST aumentou o percentual de embriões viáveis não é possível de ser explicado neste experimento. $\mathrm{O}$ fato do rbST ter elevado as concentrações plasmáticas do hormônio do crescimento (Lucy, 2000), do IGF-I e da insulina (Lucy, 2002), provavelmente se explica pelo 
efeito desses hormônios sobre maturação dos ovócitos (Pavlok et al., 1996) por efeito direto (Izadyar et al., 1998) ou pela estimulação das células da granulosa (Spicer et al., 1993), além de poderem agir nos estádios iniciais do desenvolvimento embrionário (Kim et al., 1993).

As médias gerais de $8,9 \pm 6,9$ estruturas totais e $4,68 \pm 6,0$ embriões viáveis encontradas neste estudo foram similares aos resultados de Rodrigues (2001), de 5,0 a 8,5 estruturas coletadas e 4,5 a 7,0 embriões viáveis, para tratamentos superovulatórios com $\mathrm{FSH}$ em bovinos sem especificação da raça.

A taxa de gestação não diferiu entre os tratamentos (Tab. 1). A média de $61,0 \%$ foi próxima à encontrada por Neves et al. (2001), $64,5 \%$, e superior às observadas por Moreira et al. (2002) e Bó et al. (2002), 42,9\% e 54,6\%, respectivamente. Apesar da taxa de embriões viáveis ter sido maior $(\mathrm{P}<0,05)$ nos grupos tratados com rbST, não houve reflexo na taxa de gestação das receptoras, provavelmente devido à grande variedade de fatores que interferem na taxa de gestação, entre elas a sincronia de estro entre doadoras e receptoras (Hasler et al., 1987) e a acurácia da avaliação do corpo lúteo por palpação transretal (Callesen et al., 1996).

\section{CONCLUSÕES}

A utilização de rbST antes do início da superovulação não aumentou o número de estruturas totais coletadas, mas aumentou $\mathrm{o}$ percentual de embriões viáveis, independente da dose utilizada de $250 \mathrm{mg}$ ou $500 \mathrm{mg}$, sem alterar a taxa de gestação das receptoras.

\section{REFERÊNCIAS BIBLIOGRÁFICAS}

BÓ, G.A.; BARUSELLI, P.S.; MORENO, D., et al. The control of follicular wave development for self-appointed embryo transfers programs in cattle. Theriogenology, v.67, p.53-72, 2002.

CALLESEN, H.; LIBORIUSSEN, T.; GREVE, T. Pratical aspects of multiple ovulation-embryo transfer in cattle. Anim. Reprod. Sci., v.42, p.215-266, 1996.
CUSHMAN, R.A.; SOUZA, J.C.; HEDGPETH, V.S. et al. Effect of long-term treatment with recombinant bovine somatotropin and estradiol on hormone concentrations and ovulatory response of superovulated cattle. Theriogenology, v.55, p.1533-1547, 2001.

DROST, M.; AMBROSE, J.D.; THATCHER, M.J. Conception rates after artificial insemination or embryo transfer in lactating dairy cows during summer in Florida. Theriogenology, v.52, p.1161-1167, 1999.

GONG, J.G.; BAXTER, G.; BRAMLEY, T.A. et al. Enhancement of ovarian follicle development in heifers by treatment with recombinant bovine somatotrophin: a dose-response study. J. Reprod. Fertil., v.110, p.91-97, 1997.

GONG, J.G.; BRAMLEY, T.A.; WILMUT, I. et al. Effect of recombinant bovine somatotropin on the superovulatory response to pregnant mare serum gonadotropin in heifers. Biol. Reprod., v.48, p.1141-1149, 1993.

GONG, J.G.; WILMUT, I.; BRAMLEY, T.A. et al. Pretreatment with recombinant bovine somatotropin enhances the superovulatory response to FSH in heifers. Theriogenology, v.45, p.611-622, 1996.

HASLER, J.F.; McCAULEY, A.D.; LATHOROP, W.F. et al. Effect of donor embryo recipient interactions on pregnancy rate in a large-scale bovine embryo transfer program. Theriogenology, v.27, p.139-168, 1987.

IZADYAR, F.; HAGE, W.G.; COLENBRANDER, B. et al. The promotory effect of growth hormone on development competence of in vitro matured bovine oocytes is due to improved cytoplasmic maturatuion. Mol. Reprod. Develop., v.49, p.444-453, 1998.

KIM, J.H.; FUNAHASHI, H.; NIWA, K. et al. Glucose requirement at different developmental stages of in vitro fertilized bovine embryos cultured in semidefined medium. Theriogenology, v.39, p.875-886, 1993.

KUEHNER, L.F.; RIEGER, D.; WALTON, J.S. et al. The effect of depot injection of recombinant bovine somatotropin on follicular development and embryo yield in superovulated Holstein heifers. Theriogenology, v.40, p.1003, 1993. 
LUCY, M.C. Expectativas de índices reprodutivos em vacas leiteiras tratadas com somatotropina bovina. In: CURSO NOVOS ENFOQUES NA PRODUÇÃO E REPRODUÇÃO DE BOVINOS, 6., 2002, Uberlândia. Anais... Uberlândia: [s.n.], 2002. p. $15-24$

LUCY, M.C. Regulation of ovarian follicular growth by somatotropin and insulin-like growth factors in cattle. J. Dairy Sci., v.83, p.1635-1647, 2000.

MANUAL da Sociedade Internacional de Transferência de Embriões. 3.ed. Springfield, IL: D.A. \& Seidel, SM, 1998. 180p.

MOREIRA, F.; BADINGA, L.; BURNLEY, C. Bovine somatotropin increases embryonic development in superovulated cows and improves post-transfer pregnancy rates when given to lactating recipient cows. Theriogenology, v.57, p.1371-1387, 2002.

NEVES, E.F.; MARQUES Jr., A.P.; FARIA, F.J.C. et al. Resposta superovulatória de vacas Holandesas durante as estações do ano. In:
CONGRESSO BRASILEIRO DE REPRODUÇÃO ANIMAL, 14., 2001, Belo Horizonte. Anais... Belo Horizonte, CBRA, 2001. p.381-383.

PAVLOK, A.; KOUTECKA, L.; KREJCI, P. et al. Effects of recombinat bovine somatotropin on follicular growth and quality of oocytes in cattle. Anim. Reprod. Sci., v.41, p.183-192, 1996.

RODRIGUES, J.L. Transferência de embriões bovinos - histórico e perspectivas atuais. Rev. Bras. Reprod. Anim., v.25, p.102-107, 2001.

SAMPAIO, I.B.M. Estatística aplicada à experimentação animal. Belo Horizonte: FEPMVZ, 2002. 265p.

SPICER, L.J.; ALPIZAR, E.; ECHTERNKAMP, S.E. Effects of insulin, insulin-like growth factor I, and gonadotropins on bovine granulosa cell proliferation, progesterone production, estradiol production, and insulin-like factors production in vitro. J.Anim. Sci., v.71, p.1232-1241, 1993.

WHITTINGHAM, D.G. Survival of mouse embryos after freezing and thawing. Nature, v.233, p.125, 1971. 